\title{
La oralidad en el siglo XVI: lo literario y lo privado (I). Marcadores discursivos
}

\author{
ROCÍO DÍAZ BRAVO
}

\author{
Universidad de Granada \\ $y$ \\ MARTA FERNÁNDEZ ALCAIDE
}

Universidad de Sevilla

\begin{abstract}
Resumen
El objetivo general de este trabajo es contribuir al estudio de la oralidad del español del siglo XVI como parte del espacio variacional de la lengua. Se ha analizado el uso de marcadores discursivos característicos de la oralidad concepcional (modalizadores como bien o bueno, marcadores conversacionales como mira o sí haré, y conectores como en fin o también) en dos corpus complementarios: cartas privadas escritas desde Hispanoamérica y un texto literario representativo de la mímesis de lo hablado (Retrato de la Loçana andaluza). Aunque se trata de un análisis principalmente sincrónico, no se ha desatendido la dimensión diacrónica. Como conclusión podemos destacar que los dos subcorpus tienen mecanismos y estrategias diferentes en la elaboración del discurso, por lo que el uso y frecuencia de marcadores es distinto. No obstante, al mismo tiempo, presentan características comunes que los posicionan en puntos coincidentes o aproximados de la escala gradual entre la inmediatez y la distancia comunicativas.
\end{abstract}

\begin{abstract}
This article aims to contribute to the study of orality in sixteenth-century Spanish as part of the variational space of the language. It analyses a set of discourse markers (modalizing bien or bueno, conversational mira or sí haré, and connecting en fin or también) that are typical of conceptional orality. Two complementary corpora form the database, which provides much-needed usage contexts of the markers under investigation. We use two complementary corpora of private letters written from Hispanic America and a literary text (Retrato de la Loçana andaluza) representative of the mimesis of spoken language. Although largely synchronic, diachronicoriented variation is not neglected. We conclude that though both sub-corpora have different discourse mechanisms and strategies and, therefore, reveal a difference in the usage and frequency of markers, they share common features that place them on coincident or approximate points on the gradual scale between communicative immediacy and distance in written language.
\end{abstract}




\section{Objetivos y consideraciones teóricas}

El objetivo general de este trabajo es contribuir al estudio de la oralidad del español en el siglo XVI como parte del espacio variacional de la lengua. ${ }^{1}$ De forma más concreta, se ha querido contrastar el comportamiento de una selección de marcadores discursivos característicos de la oralidad concepcional en dos corpus complementarios: un corpus de cartas privadas y un texto literario representativo de la mímesis de lo hablado (Retrato de la Loçana andaluza). ${ }^{2}$ Se parte de la hipótesis de que ambos, a pesar de sus notables diferencias, presentarían rasgos comunes característicos de lo que Koch y Oesterreicher (2007) llamaron oralidad concepcional. En efecto, siguiendo a estos autores, partimos de una oposición dicotómica en el aspecto medial, es decir, el medio gráfico frente al medio fónico, de modo que, por ejemplo, una carta y un texto literario pertenecen al mismo medio gráfico, mientras el acto de un proceso judicial o la lectura en voz alta de obras literarias se circunscriben al medio fónico. En cambio, en el nivel conceptual, existe un continuum entre el polo de la inmediatez comunicativa (oralidad concepcional) y el polo de la distancia comunicativa (escrituralidad concepcional). Koch y Oesterreicher (2007) han establecido unos parámetros comunicativos que permiten la caracterización concepcional de un discurso y su posición en este continuum entre los dos polos: grado de familiaridad entre los interlocutores, grado de planificación o espontaneidad del discurso, grado de fijación o libertad temática, grado de anclaje de la situación comunicativa, etc. Por ejemplo: una carta de un marido a su esposa, por el grado de familiaridad y espontaneidad, por la libertad temática, por la privacidad, etc., se acerca más al polo de la inmediatez comunicativa; la carta dedicatoria a un 'Illustre señor' con que se inicia RLA, por la formalidad, por la planificación del discurso, por la fijación temática, por su carácter público, etc., se acerca más al polo de la distancia comunicativa.

Para estudiar la oralidad concepcional en el siglo XVI, podemos partir de diversas fuentes (Oesterreicher 2004), entre ellas la competencia escrita de impronta oral, descuidos en la expresión escrita, la transcripción de enunciados de la inmediatez, la mímesis de lo hablado, etc. En este estudio se pretende contrastar la lengua literaria y la no literaria a través de estos textos concretos, en los que se combinan diferentes tipos discursivos ( $c f$. Pountain 2006) según esta dimensión concepcional, es decir, encontramos en ellos fragmentos de competencia escrita de impronta oral, fragmentos con descuidos en la expresión y otros,

1 Esta investigación ha formado parte de un proyecto más amplio: 'Variación lingüística y registros en el español del siglo XVI: la oralidad a través de los textos escritos', financiado por el V Plan Propio de Investigación de la Universidad de Sevilla, en colaboración con Christopher Pountain (Queen Mary, University of London), a quien agradecemos sus oportunas observaciones al texto inicial.

2 Las fuentes a las que nos referimos son las ediciones contenidas, respectivamente, en Cartas de particulares en Indias del siglo XVI: edición y estudio discursivo a cargo de Marta Fernández Alcaide (2009) (en adelante, Cartas); y en el Estudio de la oralidad en el Retrato de la Loçana andaluza (Roma, 1524), Tesis Doctoral de Rocío Díaz Bravo (2010) (en adelante, RLA). Véase también el apartado 2 . 
en los que se intenta imitar o reproducir la lengua hablada, combinados con elementos propios de las tradiciones discursivas en que se insertan estos textos. En el apartado 2 se describirán sus rasgos lingüísticos y textuales fundamentales.

Existen también divergencias no desdeñables entre estos dos conjuntos de textos, ${ }^{3}$ como el hecho de que las Cartas sean privadas y el RLA un texto literario y por tanto público, con lo que eso supone para la caracterización lingüística (conocimiento entre emisor y receptor frente a su desconocimiento, tema relativamente espontáneo frente a la planificación de $R L A$, anclaje en la situación comunicativa efectiva frente a su ausencia o su recreación, etc.), así como para la caracterización textual, pues las Cartas son documentos no impresos mientras el texto literario fue impreso y, por lo tanto, sometido a la normalización, es decir, $R L A$ carece de rasgos de escritura individuales (grafía, ortografía, puntuación, etc.) que las Cartas sí tienen.

Con objeto de cumplir nuestro propósito, se han seleccionado marcadores discursivos (teniendo en cuenta las clasificaciones de Martín Zorraquino y Portolés Lázaro (1999) y Fuentes Rodríguez (2009), fundamentalmente) propios de la oralidad concepcional: modalizadores como bien o bueno y conectores como en fin.

Somos conscientes de que esto es solamente una parcela del conjunto de los rasgos lingüísticos de estos textos ( $c f$. Borreguero Zuloaga y López Serena 2011), pero no somos ni mucho menos las primeras en relacionar los marcadores del discurso con la oposición lengua hablada/ lengua escrita (Koch y Oesterreicher 2007; Martín Zorraquino y Portolés Lázaro 1999, etc.), aunque, como señalan Borreguero y López Serena (2011: 419), 'esta frecuente constatación no haya recibido aún la atención que se merece y no contemos todavía con ningún estudio de conjunto en profundidad' (cf. Pons Rodríguez 2011: 553-55). Así pues, consideramos que los marcadores del discurso son elementos relevantes en la configuración del discurso, del tipo de texto y de la tradición discursiva de sus manifestaciones, y que, además, colaboran con la interpretación y comprensión del discurso (Aschenberg y Loureda Lamas 2011). No olvidamos que los marcadores discursivos, además de constituir variantes en la dimensión concepcional, lo son en el plano diacrónico, de ahí que no pueda restringirse su estudio a su caracterización sincrónica sino en constante relación con su funcionamiento en otras épocas.

\section{Presentación del corpus}

\subsection{Retrato de la Loçana andaluza}

El Retrato de la Loçana andaluza es una obra literaria compuesta en Roma por el clérigo andaluz Francisco Delicado alrededor de 1524. En este trabajo hemos usado la edición crítica publicada en línea como parte de la Tesis Doctoral Estudio de la oralidad en el Retrato de la Loçana andaluza (Roma, 1524) (Díaz Bravo 2010).

3 Como estudio contrastivo entre lo coloquial real y lo coloquial imitado, especialmente con relación a sus diferencias sintácticas, véase López Serena 2014 y Fernández Alcaide 2012, entre otros. 
Utilizamos esta edición no solo porque está realizada con criterios filológicos y basada en el facsímil publicado por Pérez Gómez (1950) del único ejemplar existente del Retrato ... (Díaz Bravo 2010: 385), sino sobre todo porque al tratarse de una edición electrónica preparada para el análisis automático de textos (2010: 103), nos ha permitido usar un programa de concordancias que ha facilitado mucho el análisis lingüístico.

Francisco Delicado, como ya indica desde el título de su obra, realiza un retrato no solo de su protagonista, la prostituta Loçana, sino también de los numerosos personajes (Díaz Bravo 2010: 138) que pueblan la Roma multicultural y plurilingüe anterior al famoso saqueo de 1527 . Un elemento esencial del retrato es la lengua hablada, pues Francisco Delicado caracteriza desde un punto de vista lingüístico personajes y situaciones comunicativas, ${ }^{4}$ e imita los mecanismos y estrategias de la dialogicidad oral, con objeto de aportar verosimilitud a la obra. El autor, corrector de libros en Venecia, poseía una fuerte conciencia lingüística que le permitía distinguir (aunque a veces sirviéndose de estereotipos) las características lingüísticas de judíos, andaluces, italianos, negros, etc. Se debe destacar, no obstante, que la imitación de la inmediatez comunicativa es siempre una simulación.

Por otra parte, debemos subrayar la complejidad estructural y discursiva de esta obra, hecho que la convierte en una fuente excepcional para el estudio de la variación lingüística (Anipa 2001). RLA está constituido por 66 mamotretos distribuidos en tres partes, antecedidos por una Dedicatoria y un Argumento, y seguidos por varios textos epilogales, entre ellos, algunas epístolas. Combina narraciones de acontecimientos o hechos pasados, diálogos en los que se interactúa con gran anclaje situacional, conversaciones a través de las cuales sabemos de la vida cotidiana de Roma (alquiler de una casa, compras, cocina, amores, prostitución, descripciones de la ciudad de Roma y de las personas). Asimismo, la acción se desarrolla en espacios privados (la casa), íntimos (relacionados con el oficio de la protagonista) y públicos (la calle).

Por la variedad de personajes, situaciones comunicativas, temas y tipos textuales, RLA constituye una valiosa representación de la variación lingüística del siglo XVI, mediada por la conciencia lingüística del autor literario, que es quien selecciona rasgos lingüísticos considerados propios de la lengua hablada.

\subsection{Cartas de particulares}

El corpus de cartas que se ha utilizado de base para este estudio es el editado en formato Word y publicado en CD bajo el título Cartas de particulares en Indias del siglo XVI. Edición y estudio discursivo (Fernández Alcaide 2009). Este corpus presenta como rasgo general la heterogeneidad en diversos sentidos. Se trata de un conjunto de cartas dirigidas desde diferentes puntos de Hispanoamérica a la península Ibérica entre 1540 y 1600, de marido a esposa, de padre a hijo, de hijo

4 Véase Díaz Bravo (2018), que analiza la caracterización lingüística de personajes y situaciones comunicativas en RLA. 
a padre, entre hermanos, entre cuñados, entre primos y otras relaciones menos próximas afectivamente como amigos o conocidos.

La variedad de registros está apoyada no solo en las diferentes relaciones interpersonales, el grado de familiaridad, sino también por la temática: con frecuencia las cartas están destinadas a pedir al receptor que viaje a América para reunirse con el remitente o a pedir que le sea enviado algún documento o algún material que no se encuentra en América; esto suele ir acompañado de descripciones de la nueva vida, narraciones de las aventuras y desventuras sufridas, reproches porque el receptor no ha escrito o no ha viajado según se le había pedido, saludos y mensajes personales para personas cercanas, consejos sobre lo que se debe hacer cuando se viaja a América, respuestas a mensajes de anteriores cartas, etc.

La cuestión quizá más relevante es que el corpus presenta asimismo variedad en cuanto al origen social, económico y cultural, es decir, los diferentes aspectos de lo diastrático; escriben estas cartas soldados, encomenderos, clérigos, maestros, barberos, albañiles, ganaderos, agricultores, etc.; entre ellos hay quienes sabían escribir, quienes necesitaban a un escribiente y quienes teniendo los rudimentos básicos para escribir se atrevían a hacerlo, dadas las circunstancias del Nuevo Mundo y su necesidad de comunicarse con su familia -de otro modo, no habrían escrito probablemente una carta-. Y, al mismo tiempo, presenta también variedad en lo diatópico ${ }^{5}$ y en lo diafásico. ${ }^{6}$ Todo ello nos da un panorama bastante rico de las variedades del español del siglo XVI, de las que fundamentalmente se elegirán marcadores discursivos relativos a la inmediatez comunicativa, dado el carácter dialógico de las cartas como tradición textual.

\subsection{Acercamiento tipológico}

Tras lo dicho en los dos apartados precedentes, podemos concluir, teniendo en cuenta la aproximación a la tipología textual de Oesterreicher (2004) para las variedades de la inmediatez, que los dos subcorpus son puntos distintos en esa cadena atendiendo a las diferentes condiciones comunicativas que presentan. Así, Cartas constituirían ejemplos de 'competencia escrita de impronta oral' (Oesterreicher 2004: 747), puesto que los que escriben carecen de una formación cultural suficiente por líneas generales:

Es decir, el autor que escribe (o dicta) un texto no conoce suficientemente ni la variedad lingüística exigida por el género respectivo, ni las reglas discursivas válidas para la estructuración del texto. [...] En consecuencia, el texto producido contiene, por regla general, construcciones y elementos que normalmente sólo se utilizan en el ámbito de la inmediatez comunicativa: por un lado, rasgos universales de la lengua hablada y, por otro, fenómenos que pertenecen claramente, bien a registros diafásicos o niveles diastráticos bajos, bien a variantes dialectales normalmente no

5 No solo en cuanto al lugar desde donde se escriben las cartas sino también en cuanto a la procedencia de nacimiento de sus emisores.

6 La variedad diafásica se observa, sobre todo, en cuanto a las diferentes relaciones entre emisores y destinatarios de las cartas: en general se puede afirmar que existe una mayor familiaridad entre esposos o entre padres e hijos que entre primos o sobrinos. 
admitidas en la escritura. Además, la inseguridad en el manejo de las normas lingüísticas y discursivo-textuales provoca ultracorrecciones y fórmulas fijas. (Oesterreicher 2004: 747)

Por su parte, RLA sería un caso de 'mímesis de lo hablado': 'se trata de recursos literarios que aparecen en el discurso directo, por ejemplo en una comedia o para caracterizar en una novela personajes o ámbitos' (Oesterreicher 2004: 755).

Por otro lado, atendiendo a las condiciones comunicativas y las estrategias discursivas de uno y otro subcorpus, observamos también diferencias en la caracterización en el continuo entre lo concepcionalmente hablado y escrito. La situación en Cartas la tenemos descrita en Koch y Oesterreicher (2007: 27):

a) privacidad; b) familiaridad entre los interlocutores; c) implicación emocional relativamente fuerte; d) ausencia de anclaje en la situación, quizá un anclaje limitado en la acción; e) imposibilidad, en principio, de deixis centrada en el origo del hablante, excepto con respecto al ego; f) distancia física; g) imposibilidad de cooperación en la producción; h) dialogicidad estrictamente regulada (intercambio de correspondencia); i) espontaneidad relativa; j) desarrollo temático libre.

RLA, en cuanto texto del universo literario, es de carácter público y no familiar, tiene implicación emocional pero falta de anclaje en la situación comunicativa por ser ficticio, el campo referencial como texto de ficción puede considerarse próximo al hablante pero distante en cuanto a los interlocutores, tiene débil grado de cooperación, una producción con reflexión, fijación temática y, finalmente, es de carácter monológico. Si, además, describimos las situaciones comunicativas recreadas por el autor de RLA, nos encontramos con que existen diálogos privados y familiares, con alto grado de implicación emocional y anclaje en la situación comunicativa, donde el campo referencial se basa en los hablantes, donde se recrea inmediatez física entre los interlocutores, alto nivel de cooperación y de dialogicidad, bastante espontaneidad y libertad temática. ${ }^{7} \mathrm{De}$ hecho, Francisco Delicado imita los mecanismos y estrategias de la dialogicidad oral para aportar verosimilitud a la obra, fundamentalmente, en las secuencias que pueden clasificarse como 'interacción oral prototípica' (Díaz Bravo 2010: 221-27), es decir, el tipo de discurso que mejor representa o imita la interacción oral real y que constituye más de la mitad del texto de RLA (2010: 206). No obstante, también existen otros tipos discursivos en los que el autor intenta imitar la lengua hablada (2010: 239), así como otras variedades (argumentación, exposición, narración, epístola y monólogo). ${ }^{8}$

7 Esta descripción coincide someramente con lo que López Serena (2007: 328) interpreta a partir de la caracterización de El Jarama y Entre visillos: para la autora, en estas obras que consiguen imitar con bastante fidelidad la sintaxis coloquial, se privilegian aquellos recursos sintácticos que se relacionan con los parámetros c, f, g y h, aparcando el i, esto es, los parámetros del grado de implicación emocional, el grado de proximidad o distancia física del interlocutor, el grado de cooperación entre los interlocutores y el carácter dialogal o monologal, frente al grado de espontaneidad de la comunicación.

8 Para una clasificación exhaustiva de las variedades discursivas de RLA, teniendo en cuenta los parámetros comunicativos establecidos por Koch y Oesterreicher (2007), así como su posición en la escala entre la inmediatez y la distancia comunicativas, véase Díaz Bravo 2010: 205-40. 
En cuanto a las estrategias de verbalización, ambos subcorpus tienen contextualización lingüística, si bien en Cartas en ocasiones puede haber contextualización extralingüística y en RLA en los diálogos también, como parte de la ficción; en ambos se da el carácter definitivo pero difieren en que en Cartas se observa escasa planificación generalmente y estructuración agregativa, mientras en $R L A$ la planificación es fuerte y la estructuración es integrativa. Estas diferencias en las estrategias de verbalización se van a reflejar en algunos usos de los marcadores discursivos.

\section{Análisis}

En el siguiente apartado, como se anunció en la introducción, se ha procedido a examinar algunos marcadores del discurso que podrían considerarse a priori conversacionales, dada su infrecuencia en otros textos más propios de la distancia comunicativa, como son los legislativos, los científicos, los históricos, etc.

El orden que vamos a seguir aquí será estrictamente alfabético. Si quisiéramos clasificarlos según sus valores, nos encontraríamos con que la mayoría de estos marcadores son plurivalentes o polifuncionales, precisamente uno de los rasgos caracterizadores de los marcadores discursivos de la oralidad concepcional (Borreguero Zuloaga y López Serena 2011: 444; cf. Fuentes Rodríguez 1995 y 1998), además de 'uno de los indicadores del posible cambio categorial y semántico que se está produciendo en esa fase de la evolución lingüística, como bien han mostrado los estudios de gramaticalización' (Borreguero Zuloaga y López Serena 2011: 445), de modo que podrían aparecer en más de un apartado. Para el análisis, en consecuencia, parece más coherente no establecer agrupaciones.

Por otro lado, debemos llamar la atención sobre el hecho de que las unidades estudiadas pueden tener valores y empleos completamente distintos en los dos corpus contrastados. Observaremos en cada caso si la motivación de tal circunstancia es la distinta tipología textual o la tradición discursiva o si guarda relación con otras características. Este hecho puede, además, llevar parejo que no en todos los casos haya el mismo grado de gramaticalización: así, se analizarán algunas unidades cuyo empleo como marcadores del discurso se ha comprobado solo con el devenir de la historia; pero también se mencionarán otras que se encontraban en un grado primitivo de fijación y que si finalmente hubieran podido considerarse como marcadores del discurso en el XVI, habría sido con una corta existencia.

\subsection{Bien, bueno}

Estos marcadores tienen su origen, respectivamente, en un adverbio y un adjetivo que se refieren a la bondad de algo. A partir de ahí derivan los valores como marcadores. Por un lado, en RLA, estos elementos expresan la aceptación, la confirmación o el acuerdo del hablante con el enunciado al que remiten 
(Delbecque 1994). Los siguientes ejemplos poseen un valor de conformidad, de modo que podríamos estar ante un uso de bien y de bueno como operadores modales (Fuentes Rodríguez 2009; Martín Zorraquino y Portolés Lázaro 1999: 4162; $c f$. Pons Rodríguez 2011: 592), ${ }^{9}$ aunque se puede apreciar un leve matiz de diferencia, pues mientras el primero se presenta como aceptación clara, el segundo es una aceptación como concesión en la discusión con el interlocutor o como concesión ante la propia duda del hablante:

(1)

TERESA NARBÁEZ. Mirá bien y contá mejor, que no ay entre todas nosotras quien os aya dado menos de dos. LOÇANA: Bien, mas no contáys vosotras lo que yo he puesto de mi casa. (RLA-K2r)

(2)

JODÍO: ¿Y dónde es essa casa que dezís? RANPÍN: A la Aduana. JODÍO: Bueno, ansí gozen de vos; pues no tardéys, que yo la pagaré. (RLA-D2r)

La mayoría de los casos pertenecen a fragmentos dialógicos de mayor inmediatez comunicativa, algo que se corresponde con su uso actual (Fuentes Rodríguez 2009); no obstante, bueno también aparece en un monólogo del personaje Autor:

(3)

AUTOR: [...] Yo me quiero estar aquí y ver aquel palafrenero a qué entra allá, que no estará muncho, que ya viene el notario, o nouio que será. ¡Cardico y moxama le trae el ladrón! Bueno, pues entra, que aý te quiero yo; que mejor notario es ella que tú, que ya está matriculada. Ya sale el otro; ytaliano es, mas bien habla español y es mi conoçido. (RLA-J3r)

Obsérvese que en los tres ejemplos anteriores del RLA, los dos marcadores van separados entonativamente del resto del enunciado, no solo por ir precediéndolo, sino también por la existencia de una pausa, marcada en el facsímil con el signo I, lo que confirma su calidad de marcador conversacional (Martín Zorraquino y Portolés Lázaro 1999).

Ninguno de estos valores está en Cartas y, además, no es posible comprobar si unos textos y otros comparten las características fonosintácticas anteriormente descritas, por las diferencias referidas en la introducción. No obstante, bien aparece como operador de modalidad, precediendo al verbo sin una separación entonativa y, por tanto, parece un estadio anterior a la gramaticalización observada en los diálogos de RLA. Así, sucede de forma abundante con los verbos saber, creer y parecer tanto en Cartas como en RLA. La primera combinación resulta ambigua, pues en ella bien podría interpretarse como modalizador de confirmación o simplemente como elemento cuantificador de intensidad:

(4)

TERESA: Ermana, Dios me acuerde para bien, que por sus cabellos me he acordado, que çien vezes os lo he querido dezir: ¿Acordaysos el otro día, quando fuymos a uer la parida, si vistes aquella que la seruía, que es madre de vna que vos bien sabéys? (RLA-B2v)

9 Serían el bien 4 y el bueno 5, respectivamente, según Fuentes Rodríguez (2009, s.v.). 
(5)

LOÇANA: No curéys, señora; mi marido les dará en qué ganen. TÍA: Por mi vida, y a mi marido tanbién, que bien sabe de todo y es persona sabida, avnque todos lo tienen por vn asno, y es porque no es malicioso. (RLA-C2v)

(6)

yo quedo procurando de recoger toda la mas $/{ }^{1}$ plata que posible fuere porque bien se que sera menester demas $\left.\right|^{2}$ de que yo devo (C-63)

Precediendo a decir, bien podría equivaler a modalizador de confirmación, hecho indicado por la anteposición al verbo, o a elemento cualitativo, siendo la anteposición enfática:

(7)

VIEJA. Hija, yo no querría seruir donde ay muger, que son terribles de conportar. Quieren que hiléys para ellas y que las aconpañéys. Y 'haz: aquí y toma allí, y esto no está bueno’. Y ‘¿qué hazéys con los moços?’ ‘Comé presto y vení acá!' ‘Enxaboná y mirá no gastéys muncho xabón!' ‘Xaboná estos perricos!' Y avnque xabonéys como vna perla, mal agradecido, y nada no está bien, y no miran si el ombre se uido en honrra y tuuo quien la siruiesse, sino que bien dixo quien dixo que 'no ay cosa tan ynconportable ni tan fuerte como la muger rica'. (RLA-D3v)

(8)

bien dize mi hijo mateo ruyz $\left.\right|^{10}$ que fueron mandos de pertigo de carro/ ${ }^{11}$ los que hizo alla (C-29)

Cuando bien aparece con otros verbos de opinión como creer o parecer, su relación modal es más evidente, pues el predicado no tiene un significado cualitativo ni cuantitativo; el hablante quiere reforzar el sentido positivo de su enunciación a través de esta partícula. Obsérvese en el ejemplo (11) la aparición en un mismo fragmento del adverbio en sentido cualitativo 'paréçeos bien' y en sentido modal 'bien pareçe', diferenciado probablemente gracias al orden de palabras y a la caracterización del enunciado en que se emplea, puesto que el primero es interrogativo y el segundo enunciativo:

(9)

JURISTA: ¡Voto a Dios, que a mí que me deuen desa manera más que no es de menester! Acá, a mi conpañero, no sé. Demandaldo a ella, que bien creo que passa todos los dedos y avn las tablas de la cama. (RLA-M4r)

(10)

yo lo enviare como lo ayan sus dueñas con menos $/^{1}$ riesgo . del que aora ay bien creo . que vros her $\left.\right|^{2}$ manos y mis tios an acudido mucho a vras ne/ ${ }^{3}$ çesidades y que les devo mucho (C-81)

LEONOR: ¡Abrí, puta uieja, que a saco os tenemos de dar! ¿Paréçeos bien que ha vn mes que no visitáys a vuestras amigas? ‘En puntos estamos' de daros de mazculillo. ¡Ay, qué gorda está esta putana! Bien pareçe que come y beue y triunfa, y tiene quien bien la caualgue para el otro mundo. (RLA-K2v)

a mi señora madre . le beso munchas bezes las manos $\mathrm{y} /^{28} \mathrm{q}$ bien parese qrel . se bengar de my en no escre ${ }^{29}$ birme un capitulo para mi (C-339) 
Pero interesan también aquellos otros casos donde bien se emplea con verbos que no son de opinión como poder -combinación que no se utiliza en el texto literario sino solo en Cartas-, hecho que supone ya un paso más en el proceso de fijación como operador modal:

(13)

y que vm con fauor del sor marqus $\left.\right|^{8}$ melchior de herrera aya la liçençia en consejo para esa nyña y para ${ }^{9}$ vna dueña y vna donzella que bengã con ella ella a destar en seuilla $/^{10}[\ldots]$ y aca dios le encamynara alguna buena fortun ${ }^{\mathrm{a}} /^{12}$ si vm quisiere traella hasta seuilla su hija es bien podra : $-l^{13}(\mathrm{C}-31)$

(14)

alla ynbio çerca de dos mill $\mathrm{d}^{\circ} \mathrm{s}$ [en] plata y vn podr ${ }^{9} \mathrm{p}^{\mathrm{a}}$ otros mill $\mathrm{p}^{\mathrm{o}} \mathrm{s}$ fiado q me traygan [en]pleados $\mathrm{p}^{\mathrm{a}} \mathrm{q}$ gane algo $\mathrm{p}^{\mathrm{a}} \mathrm{a} /{ }^{10}$ yuda mi yda bien pudiera ynbiar otros qtro mill $\mathrm{d}^{\circ} \mathrm{s}$ mas no quiero/ ${ }^{11}$ arresgar mas questo (C-40)

Efectivamente, en el caso de (13) bien refuerza la actitud positiva del hablante frente a su afirmación, apoyada también en la elipsis del predicado. En (14) se da una situación semejante pero en este caso bien sirve al hablante para apoyar la oposición presentada en el siguiente segmento mediante la conjunción mas, de manera que casi podría considerarse bien como correlato conjuntivo de mas, algo que por otra parte no nos extraña en este siglo.

\subsection{Cierto}

Se comporta como un modalizador epistémico. ${ }^{10}$ En nuestros ejemplos, aparece siempre al principio del enunciado, que con frecuencia es una causal de la enunciación, una explicación lógica de lo anterior. Su función es enfatizar su verdad: ${ }^{11}$

esta no sera para mas azer saber a vm comol ${ }^{1}$ quedo con salud ansi plegue a dios que sienpre $l^{2}$ lo aya de vm y de sus cosas.-çierto des $\left.\right|^{3}$ pues que a partido el senor joan de goardo me $/^{4}$ he mudado de boluntad y la pura fuerça y no $/^{5}$ poder mas me lo aze azer ansi (C-11)

(16)

yo çierto no $/^{21}$ lo determino gastarlos de no azerle mas dano $/^{22}$ en la azienda mas de aquel que hecho avn $/^{23}$ que çierto no ha zido por mi falta ni diligenzia $\mathrm{e}^{24}$ pongo a dios por testigo $(\mathrm{C}-11)^{12}$

(17)

y si determinare de quedarme conprare una muy ${ }^{21}$ buena heredad de chacara con viña de diez u doçe mil/ ${ }^{22}$ çepas y muchos arboles de castilla i de aca que me de

10 Nótese su ausencia en Fuentes Rodríguez (2009), así como en el Diccionario de partículas de Briz, Pons y Portolés (cords.) (2008).

11 Traemos aquí solamente los casos de cierto que no van seguidos de que, pues entendemos que en esos otros su valor como operador se puede ver diluido por la presencia de la conjunción.

12 En esta carta hay cinco ejemplos de cierto. 
de $\mathrm{co}^{23}$ mer quando me quiera recojer a descansar y no andar $/^{24}$ dotrinando indios que çierto es gran trabajo . pero como ${ }^{25}$ dicho pudiendo mas querria irme a España (C-175)

CAUALLERO: Monseñor, ¿qué le pareçe de la señora Loçana? Sus inxertos sienpre toman. ENBAXADOR: Me pareçe que es astuta, que, çierto, 'ha de la sierpe e de la paloma'. Esta muger sin lágrimas parará más ynsidias que todas las mugeres con lágrimas. (RLA-H1r)

Considerando, consideraua cómo las cosas que an de estar en el profundo, como Plutón, que está sobre la Sierra Morena, y las altas se abaten al baxo, como milano, que tantas vezes se abate hasta que no dexa pollo ni polla, el qual diablo de milano ya no teme espantajos, que cierto las gallinas ya no pueden hazer tantos pollos como él consuma. (RLA-N3v)

Llama la atención que en el texto literario la mayoría de ocurrencias se encuentran en el epílogo del autor, como se ve en (19), lo que nos puede hacer dudar de su empleo conversacional. Si observamos las Cartas con más detalle, cierto está en las de los hombres a sus esposas, las que intercambian los hermanos, las dirigidas a las madres, a los padres o a los hijos, los tíos, los sobrinos y los primos; pero también en cartas a personas no tan familiares a quienes se dirigen como señor o señora, como la 428, en la que Hernando Caballero escribe a Juana García, con quien había acordado tratar de convencer a su marido, Pedro Martín, de que se volviera a España; o la 436, que es de Rodrigo de León a Catalina Hernández Esquerra, a quien comunica la muerte de su marido; como en la 461, de Alonso Carrasco a Mari Gil, mujer de Bartolomé Chico de Halia, a quien se dirige como muy magnífica señora, mismo encabezamiento pero en masculino que utiliza en la 466 Alonso Hernández, espadero, para su hermano, Sebastián Hernández. Asimismo, conocemos de estos usuarios de cierto algunas profesiones: mercaderes, carpinteros, clérigos, espaderos, médicos, etc. Y, además, son tanto hombres como mujeres los remitentes.

En definitiva, la adscripción de cierto a situaciones de inmediatez comunicativa no es tan evidente, ni siquiera su empleo en contextos diafásicamente marcados como familiares o bajos. Quizá solo se pueda defender su uso en la conversación o en textos de carácter dialógico, dada la necesidad que con este marcador expresa el hablante de enfatizar y reafirmar su discurso.

\subsection{Digo, decir...}

Digo y otras variantes del verbo decir (quiero decir, dice, etc.) aparecen de forma abundante en todo el corpus, unas veces más gramaticalizadas, usadas como reformulativo y, otras veces, conservando su valor léxico. Por una parte, puede introducir una reformulación que es simple repetición de lo anterior, ya sea por un problema de audición, comprensión o inexactitud, como en el siguiente ejemplo de RLA: 
(20)

Y así esperan la luna de Boloña, que es como el socorro de Scalona; ansí que, tornando al propósito, quiero dezir que, quando a las perdidas y lisiadas y pobres y en senetud constitutas, no les dan el premio o mérito que mereçen, serán causa que no vengan munchas que vinieran a releuar a las naturales las fatigas y cansançios y conbates (RLA-J4r)

Por otra parte, encontramos ejemplos de digo en $R L A$ en los que conserva su valor léxico, cuando introduce la narración del discurso referido en estilo directo, para aclarar qué interlocutor habla:

(21)

y díxele: ‘¿Quándo viene vuestro marido, mi conpadre?'. Dize: 'Mañana'. Digo yo: ‘¿Por qué no’s ys al vaño y aconpañaros he yo?’. (RLA-M4v)

(22)

Ella, que estimaua el honor, rogome que si la sabía o podía que le ayudase, que sería d'ella pagada. 'Aquí está', digo yo, 'el marido de la tal, que por mi amor hos seruirá, y tiene excelençia en estas cosas'. (RLA-N1r)

Este empleo de digo puede verse como marca de la oralidad concepcional porque constituye una huella del proceso de elaboración y selección del discurso:

en las condiciones características de la inmediatez comunicativa [e]l alto grado de espontaneidad y de implicación emocional no permiten la planificación a largo plazo ni un avance sostenido de la información [...] El emisor tiene que contentarse, en consecuencia, con formular un discurso menos planificado y más efímero o provisional [...]. (Koch y Oesterreicher 2007: 85-86)

Finalmente, queremos señalar otros usos de digo en Cartas donde no se comporta como marcador reformulativo sino simplemente como elemento de cohesión mediante la reiteración. Entre estos, es interesante señalar algunos ejemplos como el (26) donde se utiliza digo para enfatizar el acto directo de afirmación, como acto indirecto de una promesa o una amenaza, adquiriendo, por tanto, valor performativo:

(23)

el carnero yo le $/^{19}$ ho comido mas barato alla . que no haca . porque aqui bale el arrelde $l^{20}$ real y $\mathrm{m}^{\mathrm{o}}$ y asi digo ques aca mas caro que no alla $(\mathrm{C}-83)$

(24)

alla va hernando botello $\mathrm{y} /{ }^{5} \mathrm{mi}$ maeso que vendra muy a su gusto ${ }^{6}$ como si yo viniera $[\ldots]$ ya digo $^{27}$ que botello vaya y mi maeso quellos y mi padre $\left.{ }^{28}{ }^{[12}\right]$ lo negosiaran . todo muy bien (C-102)

(25)

por eso $/^{6}$ suplico a vm que la aga venir en todo caso y venga sue her $/^{7}$ mano $\mathrm{xp}^{\circ} \mathrm{val}$ con ella y en la nao q viniere hernando bo ${ }^{8}$ tello la fletara vm que verna con el mas segura que en $\mathrm{o} /{ }^{9}$ tro cabo porq entiende los negoçios de la mar muy bien $/{ }^{10}[\ldots]$ dexan $/ /^{14}$ do dineros para el matalotagen que los fletes aca $\operatorname{los} /{ }^{15}$ pagare io i hernando botello como digo dara orden e $/^{16} \mathrm{n}$ esto (C-338) 
(26)

suplicote bien myo . vista esta ${ }^{15}$ procures en la primera . ocacion te bengas . a tu cassa que no $/{ }^{16}$ es justo . se pierda mas tienpo ny dios lo permita y para $/{ }^{17}$ que bengas como es razon digo que procureis el mejor $/^{18}$ nauio que huuiere y al senor u maestre del me obligueis $/{ }^{19}$ en quinyentos ducados y en el flete de vra persona ${ }^{20}$ y de quien binyere con bos que por esta digo y me obligo/ ${ }^{21}$ a la persona que os los diere de pagarselos en reales $(\mathrm{C}-92)$

\subsection{En fin}

Es un marcador discursivo que se comporta en nuestro corpus de tres modos diferentes. El primero de ellos, quizá el menos gramaticalizado, es el que se manifiesta cuando sirve para cerrar una enumeración de elementos o acontecimientos. Introduce, por tanto, el último componente, siendo así más próximo a su sentido literal. Este podría identificarse con el en fin 1 establecido por Fuentes Rodríguez (2009), descrito como 'conector ordenador discursivo de cierre':

Acontesçió que vna vieja auía perdido vna gallina que munchos días auía que ponía hueuos sobre vna pared, y como se encocló, echose sobr'ellos; y vino la vieja a mí que le dixese de aquella gallina, y yo estaua enojada y díxele: 'Andá, yd a vuestra casa y traeme la yerua canilla que naçe en los tejados'. Y díxeselo porque era vieja, pensando que no subiría; en fin, subió y halló la gallina. (RLA-J4v)

LOÇANA: ¡Ándate aý, puta de Tesalia, con tus palabras y hechizos! Que más sé yo que no tú ni quantas naçieron, porque he visto moras, judías, zíngaras, griegas y çeçilianas, que estas son las que más se perdieron en estas cosas, y vi yo hazer munchas cosas de palabras y hechizos, y nunca ui cosa ninguna salir verdad, sino todo mentiras fingidas. Y yo he quesido saber y ver y prouar, como Apuleyo, y en fin hallé que todo hera vanidad y cogí poco fruto, y ansí hacen todas las que se pierden en semejantes fantasías. (RLA-L2r)

El segundo valor observado es también, y más claramente que el anterior, como ordenador discursivo de cierre. A diferencia del anterior, introduce un enunciado que sintetiza las ideas previas extrayendo una conclusión, de ahí que pueda aparecer un refrán con sentido didáctico (30):

LOÇANA: Mi amor, ¿dó posáys? HERGETO: Señora, hasta agora yo y mi amo auemos posado en la posada del señor don Diego o Santiago a dormir solamente, y comer en la posada de Bartoleto; que sienpre salimos sospirando de sus manos, pero tienen esto: que sienpre siruen bien. Y allí es otro estudio de Salamanca y otra Sapiençia de París y otras Gradas de Seuilla y otra Loja de Valençia y otro Drageto a Rialto en Venecia y otra baruería de cada tierra y otro Chorrillo de Nápoles: que más nueuas se cuentan allí que en ninguna parte destas que he dicho, por munchas que se digan en Vancos. En fin, hemos tenido vna vita dulçedo y agora mi amo está aquí en casa de vna que creo que tiene bulda firmada de la cançillería de Valladolid para dezir mentiras [...]. (RLA-K3r) 
(30)

Es trugillano. Por esso dizen: 'perusino en Ytalia y trugillano en España, a todas naçiones engaña'. Este majadero ha querido descargar en mí por no pagar pontaje, y veréys que a todas hará desta manera y a ninguna pagará. Yo callaré por amor del tienpo. ‘iLa vejez de la pimienta le venga!'. Engañó a la Loçana, como que fuera yo Santa Nefixa, que daua a todos de caualgar en limosna. ¡Pues no lo supiera ansí hordir Hernán Çenteno! Si yo esto no lo platicase con alguno, no sería ni valdría nada si no lo çelebrásemos al dios de la risa, porque yo sola me sonrrío toda de cómo me tomó a manos. Y mirá que si yo entendiera a su criado, bien claro me lo dixo, que bien mirado, ¿qué me podía a mí dar vno que es estado en la posada del señor don Diego sino fruta de ospital pobre? En fin, 'la codiçia ronpe el saco'. (RLA-K4r)

deseo) $/{ }^{29}$ mucho ber a vm en esta ${ }^{30}$ tierra ) y asi entienda que si ${ }^{31}$ yo ) alla fuera ) que no avia) $/^{32}$ de benir sin vm porque es) $/^{33}$ [10]la mejor que ay en el des ${ }^{1}$ cubierto rica fertilisi $/^{2}$ ma de pan carnes pesca $/^{3}$ dos frutas quantas ay) $/^{4}$ en espana ) es tierra que $~^{5}$ jamas llueve my truena $/^{6}$ ny ay tempestades ny haze $l^{7}$ mucho frio ) ni mucha calor $\left.\right|^{8}$ no creçen los dias ny menguan $/{ }^{9}$ en todo el año y con no llover $/{ }^{10}$ como digo) se cria todo lo $\mathrm{q}^{11}$ digo ) abundantisimam ${ }^{\text {te }} / /^{12}$ porque ay rios que baxan $/{ }^{13}$ de las sierras que es donde $/^{14}$ llueve ) y con azequias riegan $/{ }^{15}$ todo lo que quieren y para $/{ }^{16}$ mỹor fertilidad embia dios ${ }^{17}$ a las noches una mollinyta muy ${ }^{18}$ menuda ) como roçio con que $/{ }^{19}$ se refresca ) toda la tierra $/^{20}$ en fin ella es tal que ningun $/{ }^{21}$ hombre la bera ) que no ol $/^{22}$ vide a españa $(C-160)$

Finalmente, observamos un tercer valor de en fin como cierre de una digresión que ha interrumpido una enumeración o narración anterior, recuperando así el hilo discursivo. Este valor solo lo hemos encontrado en las Cartas. Podría estar anunciando el valor de en fin 2 (Fuentes Rodríguez 2009) como 'conector reformulativo de corrección', en el sentido de que corrige la desviación de su discurso hacia otro tema o explica también lo precedente:

(32)

a todos mis deudos tios y tias $\mathrm{v}^{\mathrm{o}} \mathrm{s}$ y amigos beso muchas vezes las manos $\mathrm{y} /^{6}$ deseo saber muy largo de todos de mi tia ju ${ }^{a}$ despaña y de sus hijas ${ }^{7}$ deseo saber de mi tio miguel despaña y de su mujer y hijos deseo sa ${ }^{8}$ ber y de mi tia la de lucas roxo.$y$ de todos los preciados y en fin a todos $l^{9}$ les beso muchas vezes las manos y me pesa por no poder tener su quie $/^{10} \mathrm{tud} /{ }^{11}(\mathrm{C}-262)$

desde alli nos auiamos para panama, y el cap $\left.{ }^{\text {an }}\right|^{11}$ garçia de paredes me rogo que me fuese con su ropa por el rio de chagre y aunque ${ }^{12}$ se me hiço muy questa arriua lo ube de haçer porque me lo rogo mucho pero es un $/{ }^{13}$ camino de grandisimo trauajo, en fin me enbarque en nombre de dios y fue un camino $/^{14}$ donde pense mill ueçes pereçer , y acabar la uida (C-349)

En (32) sirve para detener la enumeración, no hay resumen sino corrección de la enunciación iniciada. En (33) más claramente corrige y recupera el hilo narrativo. 


\subsection{Mira, mirá, mire, miren}

El marcador conversacional mira y sus variantes mirá, mire vuestra merced, mire vuestra señoría y miren vuestras mercedes es frecuente en nuestro corpus, especialmente en $R L A^{13}$ (Anipa 2001; Company Company 2004; Pountain 2018; Sánchez Jiménez 2006). Aunque en Fuentes Rodríguez (2009) aparecen como dos entradas distintas, en este estudio no nos parece que desempeñen funciones diferentes ni tampoco que presenten particularidades que nos obliguen a separarlas.

Con mira y las demás formas se apela directamente al receptor para acercarlo al ámbito del hablante. Más que conector ordenador discursivo de interacción (Fuentes Rodríguez 2009), entendemos que es una toma de contacto entre hablante y oyente o entre remitente y destinatario. Por esta razón, mira suele ir acompañado de un vocativo: hermano, hermana, señor, señora, puta, mancebo, o el nombre de un personaje (RLA); señora mía, vuestra merced (Cartas). En RLA la lavandera emplea la forma mira (tú) dirigiéndose a su vecina en una discusión:

(34)

VIZINA: Española, ¿por qué no atas aquel puerco? No te cures, será muerto. LAUANDERA: ¡Anda uete, bésalo en el buz del yerua! VEZINA. Bien, yo te auisso. LAUAN-

DERA: Pues mira, si tú me lo miras o tocas, quiçá no será puerco por ti. (RLA-C2r)

Se usa, en cambio, la forma mirá (vos) en situaciones de intimidad entre Lozana y su novio Rampín:

LOÇANA: Pues todo esso quiero que vos me mostréys. RANPÍN: Sí haré. LOÇANA: Quiero que vos seáys mi hijo, y dormiréys comigo. Y mirá, no me lo hagáys, que esse boço d'ençima demuestra que ya soys capón. (RLA-C1r).

En Cartas no se encuentra ningún caso de mira (tú), por su parte, mirá se dirige a la esposa:

a todos me $\left.\right|^{4}$ los encomendad mira $\mathrm{sr}^{\mathrm{a}}$ mia q buestra benida sea lue $/^{5}$ go con toda brevedad (C-1)

En este ejemplo se observa una diferencia respecto del $R L A$, pues va seguido de otros elementos que sintácticamente podrían considerarse su complemento directo.

Las variantes mire y miren suelen ir seguidas de los tratamientos de cortesía vuestra(s) merced(es) o vuestra señoría, como mecanismo de atenuación a la interpelación directa al receptor. Encontramos algunos ejemplos de estas variantes tanto en RLA como en Cartas:

LOÇANA: [...] Señor, yo voy aquí en casa de vn señor que lo haga sacar. OLIUERO: Pues mire vuestra merçed, si fuere menester fauor, a monsegnor mío pornemos en ello. LOÇANA: Señor, ya lo sé. 'Salen los cautiuos quando son biuos'. ¡Ay, pecadora de mí! (RLA-G1v)

13 Para un análisis cuantitativo de mira y sus variantes, así como de otros marcadores discursivos en RLA, véase Díaz Bravo 2010: 272. 
(38)

Y mire vuestra señoría que solamente diré lo que oý y vi, con menos culpa que Juuenal, pues escriuió lo que en su tienpo pasaua (RLA-A2r)

(39)

aguame mrd de escrebir a mi ermana a sidad $/^{15}$ rodrigo i traerme respuesta cuando benga ${ }^{16}$ mire no se detengua $(\mathrm{C}-390)$

El proceso de gramaticalización de mira como marcador conversacional se encuentra en sus inicios, atestiguado en algunos ejemplos de RLA. Se trata de un elemento que refleja un rasgo universal de la oralidad (Koch y Oesterreicher 2007: 81), por manifestar la necesidad de contacto entre los interlocutores de una comunicación, aunque sea, como en las Cartas, desde la distancia física.

\subsection{Por cierto}

Comparte con el pues que veremos en seguida el valor de comentador. Por cierto ${ }^{14}$ funciona como digresor en relación con un segmento del argumento anterior (cf. Iglesias Recuero 2015), frente a pues, que hace referencia a la idea principal del enunciado precedente. Otra diferencia que se constata es que pues requiere estructura dialógica, mientras que por cierto es empleado en enunciados monológicos, como se observa en los siguientes ejemplos:

(40)

No se puede huyr a la Prouidençia diuina, pues con lo sobredicho cessan los deliquentes con los tormentos, mas no cessarán sol, luna y estrellas de prenosticar la meritoria que cadaúno aurá. Por cierto no fui yo el primero que dixo 'Ve tibi, ciuitas meretrix!'. (RLA-N5v)

(41)

avisaisme por la $/{ }^{19}$ vra que estays espantado como no me ydo a esa $/{ }^{20}$ tierra mas ayna y que no le enbiado alguna cosa $\mathrm{pa} /{ }^{21}$ ra pasar sus necesidades por cierto vm tiene $\mathrm{ra} /{ }^{22}$ çon en deçillo mas sabido por que no culpara ${ }^{23}$ porque si no fue esta carta que me escrivio el ${ }^{24}$ año pasado de 89 no e visto otra mas a de 8 años (C-229)

En nuestro corpus hemos encontrado ejemplos, de forma más abundante en Cartas que en RLA, tanto de por cierto como de su variante con que. Sin embargo, parece que el proceso de gramaticalización de este último no había culminado aún en su valor de digresor, ya que lo percibimos como modalizador epistémico, valor que procede de cierto en su uso independiente:

$(42)$

LOÇANA: Señor, hazé que lo tengáys linpio, y vntaldo con pupulión, que de aquí a çinco días no ternéys nada. CANÓNIGO: Por çierto que yo os quedo obligado. (RLA-E3r)

(43)

y si nuestra $/^{19}$ criada esta en casa y se quisiere benir con el sr ${ }^{\circ}$ su marido por $\left.\right|^{20}$ çierto $q$ yo me huelge como si fuese $\mathrm{mi} \mathrm{h}^{\circ} \mathrm{r}$ propio $(\mathrm{C}-1)$

14 Para un análisis más profundo de por cierto, véanse Acín Villa 1999; Briz, Pons y Portolés 2008; Fuentes Rodríguez 2009. En este último se observa su distribución textual en la oralidad concepcional. 
No se puede afirmar, pues, que por cierto sea ya un marcador del discurso, aunque se observa el proceso de gramaticalización iniciado. Tampoco podemos estar seguros de que caracterice la inmediatez comunicativa, como sucedía con cierto. Es quizá esa falta o escasez de planificación discursiva (Koch y Oesterreicher 2007: 30-35) lo que obliga constantemente al hablante a volver sobre sus pasos y recuperar el hilo narrativo.

\subsection{Pues}

Es un marcador discursivo polifuncional. Fuentes Rodríguez (2009: s.v.) encuentra hasta seis acepciones distintas: pues1 conector consecutivo, pues2 conector ordenador discursivo continuativo, pues3 conector ordenador discursivo interactivo, pues4 conector oposición, pues5 operador informativo y pues6 conector ordenador discursivo de cierre. Son conversacionales todos menos el primero y coloquiales, pues3, pues4 y pues6. En nuestro corpus, el pues que aparece fundamentalmente es el primero, pero no nos interesa desde el punto de vista de la inmediatez comunicativa. Aunque algunos usos de pues no son tan fácilmente clasificables, parece que no hay casos ni de pues4 ni de pues6.

Hablaremos, por tanto, de pues3. Encontramos varios ejemplos en RLA. La mayoría de los casos tiene lugar en las secuencias anteriormente denominadas como interacción oral prototípica, sobre todo, en situaciones comunicativas de mayor familiaridad o intimidad (pues3 en Fuentes Rodríguez 2009; cf. Iglesias Recuero 2000; Pountain 2018, etc.), en concreto, cuando Lozana habla con su tía sobre las recetas de su abuela (44), cuando conversa con sus paisanas andaluzas (45) o la primera noche que duerme con el que después será su novio y criado Rampín (46):

(44)

$<$ TÍA>: Sobrina, más ha de los años treynta que io no vi a vuestro padre, porque se fue niño; y después me dixeron que se casó por amores con vuestra madre, y en vos veo io que vuestra madre hera hermossa. LOÇANA: ¿Yo, señora? Pues más paresco a mi agüela que a mi señora madre; y por amor de mi agüela me llamaron a mí Aldonça; y si esta mi agüela biuía, sabía yo más que no sé, que ella me mostró guissar, que en su poder deprendí hazer fideos, enpanadillas, alcuzcuçú con garuanzos, arroz entero, seco, grasso, albondiguillas redondas y apretadas con culantro verde, que se conoscían las que yo hazía entre çiento. Mirá, señora tía, que su padre de mi padre dezía: ‘Estas son de mano de mi hija Aldonça!’ Pues ¿adobado no hazía? Sobre que quantos traperos auía en la cal de la Heria querían prouallo (RLA-A3v)

SEUILLANA: Los cabellos os sé dezir que tiene buenos. BEATRIZ: ¿Pues no veys que dize que auía doze años que jamás le pusieron garuín ni alvanega, sino vna prinçeta labrada, de seda verde, a vsanza de Jaén? BEATRIZ: ¡Ay, lóbrega de vos, amiga mía! ¿Y todo esso avéys pasado? LOÇANA: Pues no es la mitad de lo que os diré, que tomé tanta malenconía que daua con mi cabeça por tierra, y porrazos me he dado en esta cara que me marauillo que esta alxaqueca no me á çegado. (RLA-B2v/B3r) 
(46)

LOÇANA: ¡Ay, hijo! ¿Y aquí os hechastes? Pues dormí y cobijaos, que harta ropa ay. ¿Qué hazéys? ¡Mirá que tengo marido! RANPÍN: Pues no está agora aquí para que nos vea. [...] LOÇANA: ¿No os basta besarme y gozar de mí ansí, que queréis también copo y condedura? ¡Catá que me apretáys! ¿Vos pensáys que lo hallaréys? Pues hago’s saber que esse hurón no sabe caçar en esta floresta. RANPÍn: Abrilde vos la puerta, que él hará su ofiçio a la macha martillo. (RLA-C3r)

En Cartas tampoco es frecuente este valor de pues; por el contrario, lo son el consecutivo y el continuativo. Los ejemplos que vamos a ofrecer parecen ser del pues3 en partes dialógicas de las cartas, aunque la mayoría podría interpretarse también como pues4, es decir, conector de oposición, en cualquier caso del ámbito coloquial:

(47)

no e vis $/^{14}$ to carta ninguna lo qual esto $/^{15}$ con mucha pena la ocassion deue $/^{16}$ de ser por darme mas dolor q el que $/{ }^{17}$ tengo paresçeme que poco a poco $/{ }^{18}$ me va olbidando pues yo a vmd $/{ }^{19}$ no ni a mis hijos que prometo a dios $/^{20}$ que pocos son los dias que no me aquer ${ }^{21}$ do de vmd e de mis hijos (C-68)

(48)

en ninguna de sus cartas e sa ${ }^{27}$ uido de $\mathrm{hr}^{\mathrm{o}}$ ni hermana ni de nadie devo destar oluidado $/^{28}$ pues nunca mas uiuo estaua q agora doi grās a dios por ello/ ${ }^{29}(\mathrm{C}-53)$

(49)

y otros muhos q como estan ay ${ }^{26} \mathrm{q}$ no salen dentre esos navos no hablan ${ }^{27}$ con nadie , pues pregunten q cosa es la ${ }^{28}$ nueva españa y oiran lo q es $\left.\mathrm{p}[\operatorname{ar}] \mathrm{a} \operatorname{todos}\right|^{29}$ quant $^{\circ} \mathrm{s} \mathrm{y}$ mas $\mathrm{p}[\mathrm{ar}]^{\mathrm{a}}$ quien viene a descansol ${ }^{30}(\mathrm{C}-350)$

(50)

no obstante eso despues de seis años q bino/ ${ }^{31}$ le rezebi en my pta con aditam $^{\circ} \mathrm{q}$ lo pasado $^{32}$ [22]pasado le traje conmygo y traigo y el ${ }^{1}$ es el q me desonra y afrenta y me eha mis $\left.\right|^{2}$ faltas en la calle con traerle q no ay en la $\left.\right|^{3}$ tierra donde estoi mozo mas bien traido $/^{4}$ y tanto q abra dias le conpre vn solo bes ${ }^{5}$ tido $\mathrm{q}$ me costo ciento y beinte ducados $l^{6}$ y con todo no ay parar . y en lo q es no es en $l^{7}$ juego ni putas q aun no es $\mathrm{p}$ [ar]a eso ni esotro $/^{8} \mathrm{q}$ no es sino en ser malicioso mas q honbre $/^{9}[. . . ?]$ a nacido de mujer y bee bmd a $\left[\mathrm{ju}^{\circ}\right] \mathrm{p}^{\mathrm{o}} /^{10}$ ruiz de paz pues asi sera este entre nros y el $/^{11}$ tienpo le doi a vmd por $\mathrm{t}^{\mathrm{o}}(\mathrm{C}-350)$

En (47) el remitente introduce con pues una reacción comentario a la explicación que él mismo imagina de la ausencia de carta por parte de su esposa, su actual destinataria: por darle más dolor o por haberlo olvidado. En (48) parece darse el mismo valor que en el caso anterior aunque también podría interpretarse como consecutivo; el contexto de reproche es el que nos sugiere el análisis como comentador o conector interactivo. En (49) y (50), ejemplos pertenecientes a la misma carta, el remitente también introduce una idea contrapuesta a la expresada en las líneas anteriores en una situación de enfado. 


\subsection{Síharé}

Esta es una unidad que, sin duda, puede sorprender, fundamentalmente porque, si alguna vez llegó a estar totalmente gramaticalizada, no fue mucho más allá de la época estudiada. Este sintagma aparece solo en $R L A$, marcando por tanto la diferencia con las Cartas.

En RLA lo encontramos como respuesta en los diálogos. Parece tratarse de un marcador conversacional con el que se aceptan peticiones, órdenes o consejos. Una búsqueda en el Corpus Diacrónico del Español(CORDE) nos revela numerosas ocurrencias en textos literarios únicamente de los siglos XVI y XVII, con la excepción de este ejemplo del Libro del cavallero Cifar (1300-1305):

-Señora -dixo el cavallero Cifar-, tomad buen esfuerço y buen consuelo con Dios [...]

-Cavallero bueno -dixo ella-, sí faré con vuestro buen esfuerço \& con vuestro buen entendimiento.

Sí haré se emplea en la conversación coloquial en textos literarios en situaciones de enredo. Aunque su evidencia solo se encuentre en los siglos XVI y XVII, durante ese tiempo pudo tener suficiente reconocimiento como marcador. Prueba de ello es la constatación de conciencia lingüística sobre su uso en autores del Siglo de Oro, como demuestra este fragmento en que se describe a Celestina:

Murieron sus buenos precios /con la astuta Celestina, /vna matrona de España /que, en aqueste menester, /dizen que fue la muger /de mayor destreza y maña, ly que, con sólo mirar, /vna bolsa desangraua /Y, con 'sí haré', enredaua /lo que era bueno enredar. (Gabriel Lobo Lasso de la Vega, 1587. Tragedia de la destrucción de Constantinopla, apud CORDE)

Con este marcador se expresa en RLA la conformidad y el acuerdo entre los interlocutores. Además, el hablante manifiesta su intención de responder a la petición, invitación u orden de su interlocutor. ${ }^{15}$ En todos los casos aparece en situaciones recreadas de inmediatez comunicativa, de ahí su reparto textual (continuaciones de la Celestina, novela picaresca y comedias del Siglo de Oro):

TÍA [...] Comed, señora. LOÇANA: Sí haré, que hanbre tengo. <TÍA>: Oýslo, vení, asentaos junto a essa señora, que os tiene amor y quiere que os asentéys cabe ella. VIEJO: Sí haré de buen grado. (RLA-C2v)

LOÇANA: Por mi amor, que salga passico y çierre la puerta. BALIGERO: Sí haré, y besaros de buena gana. (RLA-E2r)

Ahora bien, su corta vida parece deberse a varios factores. En primer lugar, la gramaticalización de sí haré depende, sobre todo, del adverbio de afirmación, cuyo valor enfático, presente en el siguiente ejemplo, se ha mantenido hasta la actualidad:

15 Referente a las acciones de 'mostrar', 'comer', 'asentarse', 'cerrar la puerta', 'escalentar', 'llamar', 'mojar los ojos', 'ir', 'dar unos trapos', 'notar', 'cambiar' y 'hacer'. 
(55)

LOÇANA: ¿Cómo? ¿Que no ay alcagüetas en esta tierra? BALIGERO: Sí ay, mas ellas mismas se lo son las que no tienen madre o tía, o amiga muy amiga, o que no alcançan para pagar las rufianas; (RLA-E1v)

En segundo lugar, el adverbio se podía combinar con numerosos verbos ( $c f$. Rodríguez Molina 2014: 873-76) en futuro, intransitivos o transitivos sin complemento directo, como se observa en estos ejemplos de CORDE:

(56)

dize a Pánfilo: 'Mira lo que dezís, que yo creo que Arçita tú ni otro jamás en estas partes le encontrase'. Respondió Pánfilo: 'Por çierto sí encontré, e bien que se á disfigurado' (Traducción de la Teseida de Boccaccio, c 1450, apud CORDE)

(57)

DILETA Por agora te puedes ir en buen hora, ly has de dezir Aquilano /cómo dize mi señora /que venga solo y temprano. /FACETO Sí diré, /pero dime, por tu fe, lque te acordarás de mí. (Torres Naharro, Comedia Aquilana, 1524, apud CORDE)

Finalmente, el tercer factor que favorece su pérdida o la falta de una definitiva gramaticalización es la existencia de la forma sí hará. En RLA, única obra en la que lo hemos documentado con este valor, supone la aceptación de un permiso, consejo $u$ orden por parte de un personaje que actúa como intermediario de otro de condición jerárquicamente inferior, del que es responsable directo (por ejemplo: ama con respecto a su criado, como Lozana-Rampín; o madre con respecto a su hijo, como Napolitana-Rampín y Granadina-Hija):

LOÇANA: Esso querría yo si me mostrasse este niño la casa. CAMISERA: Sí hará. Ven acá, Aguilarico. (RLA-B3v)

(59)

¿Qué haze vuestra hija? ¿Pússose aquello que le di? GRANADINA: Señora, sí, y dize que muncho le aprouechó, que le dixo monseñor: ‘Qué coñico tan bonico!' LOÇANA: Pues tenga ella auertençia que, quando monseñor se lo quiera meter, le haga estentar vn poco primero. GRANADINA: Sí hará, que ya yo la auissé, avnque poco sé desso, que a tiento se lo dixe. (RLA-F4r/v)

En definitiva, nos encontramos con una unidad característica de los textos literarios que no está totalmente gramaticalizada y que no sobrevivió al español del Siglo de Oro.

\subsection{También}

También es un conector continuativo que parece caracterizar la lengua hablada. Así lo señalan Bustos Tovar (2002), Cano Aguilar (2001) o Eberenz (1994) para los textos del siglo XV. Probablemente lo distinguidor de la oralidad no es tanto su aparición como su abundancia, en contrapartida, su selección frente a otros conectores continuativos menos frecuentes en la oralidad concepcional. Es curioso, en ese sentido, que en el texto literario estudiado no aparezca más que 
una vez con este valor -pues la continuidad se apoya en otros elementos, sobre todo, en la deíxis-, frente a la abundancia con la que es empleado en Cartas. En ellas se observa que no hay un reparto diatópico, diastrático ni diafásico. Es probable, por tanto, que el autor de la Lozana no lo sintiera como característico del diálogo. Aunque ya pueda considerarse iniciada una tradición discursiva en la literatura de imitación de la oralidad (Bustos Tovar 1996 y 1998), todavía queda mucho para que quede configurada y son apenas unos cuantos rasgos los que se reflejan, eliminando, pues, la mayor parte de estrategias de la oralidad concepcional:

(60)

AUTOR: ¿Cómo? ¿Y su madre la traxo a Roma? RANPÍN: Señor, sí, para ganar, que era pobre. Tanbién la otra vuestra muy querida dize che ella os sanará. (RLA-D2r)

Veamos algunos ejemplos de las Cartas. El primero que ofrecemos pertenece a una carta dirigida a un hermano; en el fragmento precedente le pedía con deseo e insistencia a su hermano que se fuera con él para poder así vivir mejor. También le sirve para enlazar dos acontecimientos de su vida que está narrando como justificación por no enviar más dinero:

(61)

con el $\operatorname{cap}^{\mathrm{n}}$ vera embie a nuestra $\mathrm{m}^{\mathrm{e}}$ quinientos escudos ${ }^{20}$ y embiare mas pero como ando negoçiando habriame hecho ${ }^{21}[5]$ mucha falta tambien ando por casarme $\left.\right|^{1}$ quiera nro señor lo endereze como mejor fuera $/^{2} \mathrm{p}$ [ar]a su sancto servy ${ }^{\circ}$ desto os tengo muy largo/ ${ }^{3}$ con la acussada avisado (C-248)

La siguiente muestra es un fragmento de una carta a un sobrino, es el inicio. Se observa que también está uniendo los dos encargos que le hace el tío al sobrino: el primero es que se vaya con él pero va acompañado de varias excusas y varias cortesías que lo separan suficientemente del segundo, que no se case, para estar más libre para viajar. Los dos encargos están, pues, en la misma línea argumentativa, en igualdad, también no añade nada, solo los une:

tres o quatro cartas hos he escripto por cada $\left.\right|^{1}$ vna dellas rogandos me hiçieseis plaçer de venir $/^{2}$ a esta çiudad / de mexico en donde yo viuo con deseo/ ${ }^{3}$ de aprouecharos pues entiendo padeçereis neçesi $/^{4} \mathrm{dad}$ hauiendo quedado vos con vras hermanas $\left.\right|^{5}$ quando yo me parti sin padres lo qual todas las ue $\left.\right|^{6}$ çes q me pongo a considerarlo me llega al ani $/^{7}$ ma y siempre os hubiera embiado alguna cosa ${ }^{8} \sigma \mathrm{i}$ entendiera herades viuos mas como nunca aya ${ }^{9}$ visto carta de vosotros estoi tibio tambien hos en $/{ }^{10}$ cargaria nos casasedes $\sigma$ in mi licençia y aceldo ansi $/{ }^{11} \mathrm{q}$ no perdereis nada teniendo como tendreis vos y vras ${ }^{12}$ hermanas en mi vn buen padre $(C-369)$

La tercera muestra es de una carta iniciada con señora, que probablemente sea su cuñada, mujer de su hermano, a quien escribe dando un mensaje para su hermano. Aquí también sirve para unir pero son dos elementos que no se encuentran en paralelo, como los anteriores, son dos enunciaciones con igualdad de fuerza argumentativa (Fuentes Rodríguez 2009: 331): 
(63)

a mi ermano geronimo gonçalez estoy $/^{11}$ muy qjoso q de çinco años a este cabo no e rebido $<$ sic $>\operatorname{sino} /^{12}$ dos cartas suyas . no se que es la causa de no acordarse $/^{13}$ de mi biniendo cada seis meses flota a esta tierra ${ }^{14}$ tambien le he escrito en dos cartas que en sabiendo su hijo $/^{15}$ andresico escrebir y contar me le enbie porq aliende de $l^{16}$ abelle menester para mis negoçios terne gran contento $/{ }^{17}$ en tenelle aca $\mathrm{pa}^{\text {ra }}$ si dios dispusiere de mi tener a quien ${ }^{18}$ dejar mi açienda (C-427)

Algo similar sucede en este otro ejemplo, que es de una carta a un cuñado a quien se refiere como señor:

(64)

vna de vmd reçivi y con ella mucho contento en sav[er] de $/^{1}$ la salud de vmd y de la señora mi hermana y por hotra $/^{2}$ parte ) mucho descontento en v[er] q q aqlla veatriçica an $/^{3}$ duviese tan desvaratada sea dios vendito por todo quiça son/ ${ }^{4}$ nros pecados rogar a dios la trayga a vuen conoçimiento $\mathrm{pa} /{ }^{5}$ ra q se enmiende tanvien me escrive vmd q los quaren/ $/$ ta ps q llevo diego de pastrana no los a dado (C-435)

En efecto, en este comienzo se refiere a una carta, recibida previamente, del actual destinatario, es por tanto una respuesta. En primer lugar aparece la alusión a la salud de la familia y después a la recepción del dinero enviado. No son, por tanto, dos cuestiones relacionadas entre sí más que por el hecho de ser respuesta al contenido de otra carta. Es simple suma que señala a un elemento anterior con el que se encuentra en equidad argumentativa e informativa.

\section{Conclusiones}

Como ya se señaló al principio, los dos subcorpus, RLA y Cartas, tienen mecanismos y estrategias diferentes en la elaboración del discurso; se circunscriben a tradiciones discursivas distintas, es decir, ambos están sujetos a unas condiciones estructurales que les vienen dadas por una o varias tradiciones discursivas propias; difieren también por el hecho de ser uno un texto de ficción y el otro real, característica que tiene consecuencias directas sobre sus diversos propósitos comunicativos. Por tanto, el uso y la frecuencia de marcadores son distintos. Así lo hemos observado en la descripción de bien, bueno o digo, aparentemente más gramaticalizados en la obra literaria que en las Cartas; en mira y todas sus variantes, del que hemos constatado mayor frecuencia de uso en RLA que en Cartas; o en cierto, cuya consideración en sí mismo como propio de la inmediatez comunicativa se ha puesto finalmente en duda, si bien se ha asociado al mayor grado de implicación emocional de los remitentes de Cartas, del mismo modo que por cierto, más frecuente en Cartas que en $R L A$, se ha relacionado con la escasez de planificación discursiva. Diferentes son también los dos subcorpus en lo relativo a sí haré, unidad característica de los textos literarios del Siglo de Oro que solo aparece en nuestro corpus en RLA y, además, sin estar totalmente gramaticalizada.

Al mismo tiempo, presentan características comunes por el hecho de que ambos corpus comparten varios parámetros comunicativos que los posicionan en puntos 
coincidentes o aproximados de la escala gradual entre la inmediatez y la distancia comunicativas: el uso de pues es un claro ejemplo de ello pero, asimismo, aunque sea con diferente proporción en su aparición, mira y sus variantes, o también.

Por último, a pesar del interés que sin duda suscita el estudio de la variación diatópica, todavía no se aprecian diferencias que permitan rastrear, a través del estudio de marcadores discursivos en las cartas, algunos rasgos incipientes del español que se estaba fraguando en América en aquella época, frente al español peninsular ni frente al español hablado en Italia reflejados en el texto literario escrito en Roma. La misma conclusión podemos extraer con respecto a la variación diastrática en relación con los marcadores discursivos analizados.

Este trabajo constituye una aportación al estudio de la variación lingüística del español del siglo XVI, en lo referente a algunos marcadores discursivos caracterizadores de la oralidad concepcional, a través de un corpus que permite analizar rasgos de inmediatez comunicativa: cartas privadas escritas desde Hispanoamérica y un texto literario representativo de la mímesis de lo hablado, el Retrato de la Loçana andaluza, sin perder de vista la dimensión diacrónica que afecta tanto a la configuración de los textos utilizados para el estudio, como a las unidades lingüísticas seleccionadas en el análisis.

\section{Obras citadas}

\section{Fuentes primarias}

Cartas: Fernández Alcaide, Marta, 2009. Cartas de particulares en Indias del siglo XVI: edición y estudio discursivo (Madrid/ Frankfurt am Main: Iberoamericana/ Vervuert).

CORDE (Corpus Diacrónico del Español). [En línea - Real Academia Española.] Disponible en: $<$ http://corpus.rae.es/cordenet.html> [consultado el 6 de febrero de 2018].

RLA: Díaz Bravo, Rocío, 2010. Estudio de la oralidad en el Retrato de la Loçana andaluza (Roma, 1524). Tesis Doctoral, Universidad de Málaga. Versión en CD-ROM del Servicio de Publicaciones de la Universidad. [En línea.] Disponible en: <http://riuma.uma.es/xmlui/ handle/10630/4575> [consultado el 14 de enero de 2018].

\section{Fuentes secundarias}

Acín Villa, Esperanza, 1999. 'Por cierto, a propósito y otros digresivos', en Lengua y Discurso: Estudios dedicados al profesor Vidal Lamíquiz, coord. P. Carbonero, M. Casado Velarde y P. Gómez Manzano (Madrid: Arcol Libros), pp. 59-72.

Anipa, Kormi, 2001. A Critical Examination of Variation in Golden-Age Spanish (Nueva York: Peter Lang).

Aschenberg, Heidi, y Óscar Loureda Lamas (eds), 2011. Marcadores del discurso: de la descripción a la definición (Madrid/ Frankfurt am Main: Iberoamericana/Vervuert).

Borreguero Zuloaga, Margarita, y Araceli López Serena, 2011. 'Los marcadores del discurso y la variación lengua hablada vs. lengua escrita', en Los estudios sobre marcadores del discurso, hoy, coords. Óscar Loureda Lamas y Esperanza Acín Villa (Madrid: Arco/ Libros), pp. 415-95.

Briz, Antonio, Salvador Pons y José Portolés (coords.), 2008. Diccionario de partículas discursivas del español [En línea.] Disponible en: <http://www.dpde.es/> [consultado el 5 de febrero de 2018].

Bustos Tovar, José Jesús de, 1996. 'La imbricación de la oralidad en la escritura como técnica del discurso narrativo’, en El español hablado y la cultura oral en España e Hispanoamérica, ed. Thomas Kotschi, Wulf Oesterreicher y Klaus Zimmermann (Frankfurt am Main y Madrid: Vervuert / Iberoamericana), pp. 359-74. 
—, 1998. 'Lengua viva y lenguaje teatral en el siglo XVI: de los pasos de Lope de Rueda a los entremeses de Cervantes', en Competencia escrita, tradiciones discursivas y variedades lingüísticas. Aspectos del español europeo y americano en los siglos XVI y XVII, eds. Wulf Oesterreicher, Eva Stoll y Andreas Wesch (Tübingen, Alemania: Narr), pp. 421-44.

-, 2002. 'Mecanismos de cohesión discursiva en castellano a fines de la Edad Media', en Actas del V Congreso Internacional de Historia de la lengua española, ed. María Teresa Echenique y Juan Sánchez (Madrid: Arco/ Libros), pp. 53-84.

Cano Aguilar, Rafael, 2001. 'La cohesión gramatical del discurso en el castellano del siglo XV', en Indagaciones sobre la lengua. Estudios de filología y lingüística española en memoria de Emilio Alarcos Llorach, ed. Elena Méndez, Josefa Mendoza y Yolanda Congosto (Sevilla: Universidad de Sevilla, Secretariado de Publicaciones), pp. 181-201.

Company Company, Concepción, 2004. ‘¿Gramaticalización o desgramaticalización? Reanálisis y subjetivización de verbos como marcadores discursivos en la historia del español', Revista de Filología Española, 84.1: 29-66.

Delbecque, Nicole, 1994. 'Las funciones de así, bien y mal. De la diferencia entre "como bien sabe todo el mundo", "se vive (bastante) bien en Europa”, "así lo pienso” y “es así”, Revista Española de Lingüística, 24.2: 435-66.

Díaz Bravo, Rocío (ed.), 2018. Francisco Delicado, Retrato de la Loçana andaluza. A Critical Edition with Introduction and Notes. Critical Texts, 56 (Cambridge: Modern Humanities Research Association).

Eberenz, Rolf, 1994. 'Enlaces conjuntivos y adjuntos de sentido aditivo del español preclásico: otrosí, eso mismo, asimismo, demás, también, aun, etc.', Iberorromania, 39: 1-20.

Fernández Alcaide, Marta, 2012. 'El diálogo en Fray Gerundio de Campazas y la relación oralidad-escrituralidad', en Oralia, 15: 147-75.

Fuentes Rodríguez, Catalina, 1995. 'Modalidad y conexión en el español coloquial', Español Actual, 63: 5-24.

-, 1998. 'Vamos: un conector coloquial de gran complejidad', en Los marcadores del discurso. Teoría y práctica, coords. María Antonia Martín Zorraquino y Estrella Montolío Durán (Madrid: Arco/ Libros), pp. 177-92.

-, 2009. Diccionario de conectores y operadores del español (Madrid: Arcol Libros).

Iglesias Recuero, Silvia, 2000. 'La evolución histórica de pues como marcador discursivo hasta el siglo XV', Boletín de la Real Academia Española, 80/280: 209-305.

-, 2015. 'Sintaxis, texto y discurso: la historia de por cierto', en Les Marqueurs du discours dans les langues romanes: une approche contrastive, eds. Margarita Borreguero Zuloaga y Sonia GómezJordana Ferary (Limoges: Lambert-Lucas, Universidad Complutense de Madrid), pp. 251-84.

Koch, Peter, y Wulf Oesterreicher, 2007. Lengua hablada en la Romania: español, francés, italiano, trad. del alemán por Araceli López Serena (Madrid: Gredos).

López Serena, Araceli, 2007. Oralidad y escrituralidad en la recreación literaria del español coloquial (Madrid: Gredos).

-, 2014. 'De la oralidad fingida a la oralidad simuladora de realidad. Reflexiones en torno a la coloquialización del discurso como estrategia mediática', Español Actual, 102: 37-76.

Martín Zorraquino, María Antonia, y José Portolés Lázaro, 1999. 'Los marcadores del discurso', en Gramática descriptiva de la lengua española, vol. 3, eds. Ignacio Bosque y Violeta Demonte (Madrid: Espasa-Calpe, Real Academia Española), pp. 4051-4213.

Oesterreicher, Wulf, 2004. 'Textos entre inmediatez y distancia comunicativas. El problema de lo hablado escrito en el Siglo de Oro', en Historia de la lengua española, ed. Rafael Cano Aguilar (Barcelona: Ariel), pp. 729-69.

Pérez Gómez, Antonio, 1950. Edición facsímil del Retrato de la Loçana andaluza, en lengua española, muy clarissima. Compuesto en Roma, Venecia. Valencia, Talleres de Tipografía Moderna. [En línea - Biblioteca Virtual Miguel de Cervantes.] Disponible en: <http://www.cervantesvirtual.com/FichaObra.html?Ref=10776> [consultado el 14 de enero de 2018].

Pons Rodríguez, Lola, 2011. 'Los marcadores del discurso en la historia del español', en Los estudios sobre marcadores del discurso, hoy, coords. Óscar Loureda Lamas y Esperanza Acín Villa (Madrid: Arco/ Libros), pp. 523-615.

Pountain, Christopher J., 2006. 'Towards a History of Register in Spanish', Spanish in Context, 
-, 2018. 'Variation and the use of discourse markers in 16th-century Spanish', en Studies in Historical Ibero-Romance Morpho-Syntax, eds. Miriam Bouzouita, Ioanna Sitaridou y Enrique Pato (Amsterdam: John Benjamins), pp. 303-24.

Rodríguez Molina, Javier, 2014. 'La gramática oculta de la polaridad positiva en español antiguo', RILCE, 30.3: 861-915.

Sánchez Jiménez, Santiago U., 2006. 'Intercambios comunicativos en el español clásico (tras los Pasos de Lope de Rueda)', Romanistisches Jahrbuch, 57: 352-77. 
